\title{
Service Quality and Prospects for Benchmarking: Evidence from the Peru Water Sector
}

\author{
Chen Lin* \\ Research Associate, Public Utility Research Center, \\ University of Florida, P. O. Box 117142, Gainesville, FL 32611-7142 \\ Revised April 25, 2005
}

\begin{abstract}
Service quality is a very important aspect of the water and sewerage industry. Empirical studies have tended to focus on production costs, without explicitly introducing key dimensions of quality. Using data from the Peruvian water sector (1996-2001), this study examines how the introduction of quality variables affects performance comparisons across utilities. The research presents different specifications of stochastic cost frontier models to illustrate how quality can be incorporated into benchmarking studies.
\end{abstract}

Keywords: Water sector; Service quality; Stochastic Frontier models

\section{Introduction}

The goal of public utility reform is to improve sector performance. Water utilities present a unique set of issues since they have the characteristics of natural monopolies and are often publicly owned. In developing countries, reforms arise in two ways: regulatory reform and ownership reform. In the regulatory reforms, new commissions have adopted a variety of incentive mechanisms designed to replicate the disciplines of competitive markets. ${ }^{1}$ Whether

\footnotetext{
* The author is grateful to the editor and to unidentified referees for providing valuable suggestions for improving an earlier draft. He accepts responsibility for remaining mistakes or errors of judgment. E-mail address: chen.lin@cba.ufl.edu. Tel.: 352-392-6148; fax: 352-392-7796.

${ }^{1}$ Even in OECD countries, private ownership of water is much less prevalent than in other utility sectors. For instance, privatization of water was highly controversial in England and Wales. In Australia, many utilities were privatized, but not water, since this was deemed "going too far".
} 
rate-of-return or price cap regulation is adopted, some form of yardstick regulation is often utilized to establish targets and to promote cost containment, network expansion, financial sustainability, and quality of service improvements. The performance record to date is somewhat mixed.

Regulators often do not have the instruments to provide adequate incentives to meet objectives. Nevertheless, benchmarking has become a tool that can be used to inform the public debate over infrastructure improvements. Thus, incorporating service quality into the regulatory evaluation represents a refinement that warrants attention if political leaders, utility managers, and citizens are to have a good understanding of utility performance. For example, quality can be an important issue in Total Factor Productivity (TFP). Saal and Parker (2001) showed that TFP change in the water sector in the United Kingdom has been extremely slow in recent years, but the quality has improved significantly because of the large increases in minimum standards. Improving this dimension of output involved significant costs. Thus, the use of unadjusted TFP change measures during this period would understate the actual TFP improvements.

In the ownership reforms, private participation is often viewed as beneficial for expanding access and for improving operations, but privatization still raises social concerns in many emerging markets. Private investment has lagged in the water and sewerage sector, where (1) technological change has lagged (relative to energy and telecommunications), (2) the majority of the assets are fixed and long-lived, (3) current prices are often below operating costs, (4) political 
barriers to reform are strong, and (5) local governments often play a major role in the provision of services. Despite the obstacles, private activity in water and sewerage grew significantly in 19902001 as forty-three developing countries (mostly in the Latin America/Caribbean and East Asia/Pacific regions) awarded more than two hundred projects with private participation, attracting investment commitments of almost $\$ 40$ billion (World Bank 2003).

With regulatory and ownership reforms, benchmarking (or yardstick competition) becomes an important tool for evaluating the effectiveness of the reforms and comparing the relative performance of different companies within the sector. Rankings help inform the public, directing attention toward poorly performing utilities and providing information to policy-makers and regulators regarding deviations from best practice. In addition to traditional measures of technical efficiency, service quality is a performance indicator that warrants attention. ${ }^{2}$ The World Commission on Water estimated that mitigating water and sanitation problems (which often affect public health) would require US\$600-800 billion between 2000 and 2010 (Clark et al. 2004). To examine the benefits of incorporating quality variables into benchmarking, this paper uses stochastic cost frontier models to illustrate how performance rankings might be affected

\section{Literature Review}

Relative and absolute rankings can become catalysts for better stewardship of water and other resources. With increasing demand, rising public expectations, and natural experiments

\footnotetext{
${ }^{2}$ Foster (2005) emphasizes quality-of-service regulation (especially potability, pressure, and continuity) as a complement to price regulation.
} 
(reforms), scholars are beginning to explore the impact of regulation, franchise competition, and privatization on infrastructure performance and efficiency. Less attention has been given to water, partly because of data availability issues. Recent studies draw upon data from developed and developing countries.

Literature in developed countries: Scholars in the United Kingdom have given substantial attention to the water sector. Hunt and Lynk (1995), Cubbin and Tzanidakis (1998), and Ashton (2000) focus on estimating the efficiency of water utilities using a variety of techniques. Hunt and Lynk examine the extent to which the integrated authorities benefited from joint production by using a dynamic multi-product cost function based on UK panel data from 1979/80-1987/88. Cubbin and Tzanidakis compare the results of analyses utilizing DEA and regression analysis. Ashton calculates the relative efficiency of ten privatized UK water and sewerage companies between 1987 and 1997, using a fixed-effect cost function with data from England and Wales. More recently, Saal and Parker $(2000,2001)$ underscore the importance of quality issues. They check the impact of privatization and regulation on the productivity growth and total cost of the water sector in England and Wales using quality adjusted outputs (adjusted by indices of the relative quality of drinking water and sewerage treatment). Some of their recent working papers (Saal and Scott (2004); Saal et al. (2004) and Saal and Parker (2005)) also use the quality adjusted variables in the estimation of translog cost functions and input distance functions. ${ }^{3}$

\footnotetext{
3 A number of studies of U.S. water utilities are summarized in Wallsten and Kosec (2005). Using data on the quality of water 1997-2003, they test the effects of ownership and benchmark competition on regulatory compliance and household water expenditures: "Public systems are somewhat more likely to
} 
Literature in developing countries: As data have been available, scholars are beginning to apply parametric and non-parametric techniques to examine the impacts of policy change and to evaluate utility efficiency. Using 1995 data from fifty water companies in nineteen Asian countries, Estache and Rossi (2002) examine effects of ownership on utility performance and find significant differences between private and public water utilities. Using the data from 21 water utilities in 16 African countries, Estache and Kouassi (2002) find that the private operators are more efficient than public operators. Estache and Trujillo (2003) find a significant improvement resulting from 1990s reforms in the sector: one of the renationalized companies is managing to maintain gains achieved under private operation. Kirkpatrick et al. (2004) use data for 71 African water utilities to explore the effect of ownership on technical efficiency. They find no significant evidence of difference between ownership types. Tupper and Resende (2004) use the non-parametric linear programming method, Data Envelopment Analysis (DEA), to provide efficiency scores for twenty Brazilian state water and sewage companies during 1996-2000. Based on the DEA and econometric methods, they propose a procedure to construct a linear reimbursement rule that constitutes a yardstick competition mechanism. Using a large database (sample size about 4000), Seroa da Motta and Moreira (2004) also employ DEA models to evaluate water municipalities of Brazil during the period 1996-2002. They find that private

violate the maximum levels of health-based contaminants allowed under the Safe Drinking Water Act (SDWA), while private systems are somewhat more likely to violate monitoring and reporting regulations. The results are reversed for systems that serve more than 100,000 people." 
operators stimulate catching up, but they find no significant difference between public and private operators in terms of total variation in productivity. Regional operators benefit from scale economies but have the lowest productivity levels. Alva and Bonilaz (2001) use DEA approach to rank the Peru water utilities for a 3 years period. (1998-2000). Corton (2003) uses a cost function regression model to evaluate Peruvian water utilities.

In other sectors, Estache et al. (2004) use a quality incorporated Malmquist productivity index to explore the impact of privatization on the quantity-quality tradeoff in Brazil railway industry. The result shows that private operators have improved efficiency in terms both quantity and quality. Using similar techniques and focusing on U.K. electricity distribution companies, Giannakis et al.(2005) find that cost-efficient firms do not necessarily exhibit high service quality: improvements in service quality have made a significant contribution to sector's total productivity change. They argue that integrating quality of service in regulatory benchmarking is preferable to cost-only approaches.

In addition to empirical studies, ${ }^{4}$ there are numerous theoretical analyses of service quality. Sappington (2005) provides a comprehensive survey of the theoretical literature regarding the design of service quality regulation in public utility industries. In a very simple setting (single dimension of quality, q), he summarizes why an unregulated monopoly will not necessarily deliver the welfare-maximizing level of quality. Theoretically, the unregulated monopolist will

\footnotetext{
${ }^{4}$ Estache et al. (2005) provide a comprehensive survey of the recent productivity and efficiency literature in infrastructure industries (energy, ports, railways, roads, telecommunications and water\& sewerage) in developing countries.
} 
supply more than welfare-maximizing level of quality if the marginal customer values additional quality more highly than do infra-marginal customers on average. In practice, excess supply of quality may be a potential problem in developed country. However, this result is unlikely in a developing country such as Peru. As we will see in the following sections, water availability are service coverage are very poor in Peru compared to the developed country. To improve service quality is a very important objective for the Peruvian water regulator.

This paper extends the current literature in service quality research of water industry. Like Corton (2003), the present study examines the performance of the publicly-owned water utilities (Empresas Proveedoras de Servicios_EPS) regulated by SUNASS in Peru. ${ }^{5}$ Using data from 1996-2001, this study attempts to determine whether the inclusion of quality indicators into the estimation affects the benchmarking results.

\section{Background and model specification}

Policy-makers and water regulators in Peru face problems of inadequate system maintenance, a high level of unaccounted-for water, excess staff, low metering rates, and low water quality. The lack of readily available comparative data about quality, operation costs, prices, quantity, and service coverage makes it hard for customers to exert pressure on the water utility managers to

\footnotetext{
${ }^{5}$ The dependent variable in Corton's regression model is operation cost; the independent variables are volume of water produced, the length of mains measured in kilometers, the number of districts administered by each company and two dummies for regions. One drawback of the model is that the input prices are not included in the cost function. Second, the estimation is based on the deterministic model, which assumes that all deviations of individual firm performance from the frontier are attributable to inefficiency rather than to random factors beyond the managers' control. Third, service quality differences are omitted.
} 
improve their performance. In late 1999, SUNASS established a benchmark system under the guidance of a World Bank consulting group as a first step toward informing citizens and political leaders about the relative performance of the municipal utilities. The group selected nine indicators, grouping them into four areas of efficiency.

1. Quality of Service includes three variables: compliance with the residual chlorine rule, continuity of service, and percentage of water receiving chemical treatment.

2. Coverage of Service Attained consists of two variables: water coverage and sewerage coverage.

3. Management Efficiency reflects three variables: operating efficiency (a combination of continuity of service and the volume of water produced to serve each person in a connection), percentage of connections with meter installed, and the ratio of bills not yet collected to the total number of bills (nonpayment).

4. Managerial Finance Efficiency is defined by the ratio of direct costs and other expenses to revenues.

The first two broad areas of efficiency represent the interests of society. The third reflects the companies' performance, and the fourth represents the citizen-owner's perspective. Each of the nine sub-indicators was assigned a weight of 1 as a first step in the benchmarking process. Each indicator expressed as a percentage is multiplied by its weight and added to the percentage total per company. This total per company is divided by nine, the number of indicators. ${ }^{3}$

There are some potential problems with this approach to evaluating performance. With an 
equal weight of 1 assigned to each of the nine indicators, there is no differentiation among the different performance dimensions, although some are (presumably) more highly valued than others. More importantly, most indicators in the SUNASS scheme lack ${ }^{6}$ input-output causative relationships. Only the managerial efficiency category considers the cost issue. The basic definition of productivity is equal to outputs/inputs (where identifying the weights and addressing index number issues raises analytical problems). The benchmarking scheme in Peru is actually output-oriented and does not incorporate inputs in a comprehensive manner.

In this study, the stochastic cost frontier models will be used to explore the impact of service quality variables on the firm efficiency evaluation. Cost depends on input prices technology and outputs (where the production technology determines the appropriate levels of inputs). For this study, total cost is calculated from the SUNASS database by adding cost of sales, sales expense, administrative expense, financial cost and depreciation (the sum serves as an approximation for annual capital costs). The outputs are those used in many water studies: volume of water billed and the number of customers. Because volume of water billed is highly correlated with revenue, it is not included as an output.

The two input prices are wage and capital price. The wage is calculated by total outlays on labor divided by the number of employees. The number of the employees is equal to the sum of the permanent workers and contract workers. Because all the water utilities in Peru are

${ }^{6}$ For more detail information about Peru water sector, readers are referred to Corton (2003) and Foster (2005). 
government owned, excessive labor may be a serious problem due to weak managerial incentives for cost containment and interference by local politicians. The mean value of the ratio of staff per 1000 connections is 6.04 , which is significantly higher than the mean value of the ratio (2.1) in developed countries, although relative input prices also differ across countries (Tynan and Kingdom 2002).

The price of capital is perhaps the most difficult variable to calculate for cost functions in developing countries. The rental price of capital can be approximated by annual capital outlays divided by the capital stock. These outlays are not new capacity investments but returns required for financial sustainability. In this study, capital outlays are approximated by adding depreciation and financial cost (interest payments). Either the network length or the number of water connections can be used as the proxy for cumulative capital investment (stock of capital). The number of connections is used as a proxy for capital stock since there is a serious problem with missing data for network length in 1996-97. The ratio should reflect relative price of capital across utilities even though there are, no doubt, measurement errors for this variable. Because of a lack of data on fuel, chemicals, and power and material costs, the model does not impose the restriction of homogeneity of degree one in prices for estimation purposes.

Quality of service is another potential output or control variable since a firm can always lower its costs by reducing its service quality. Service quality is quite heterogeneous and, in general, relatively low. Four variables are used to capture different dimensions of service quality: Accounted-for water ratio, positive rate of chlorine tests, service coverage and service continuity. 
The accounted-for water ratio is equal to 1 minus the unaccounted-for water ratio-the difference between water supplied and water sold as a percentage of water supplied. As Tynan and Kingdom (2002) point out, the unaccounted-for water ratio captures commercial losses attributable to inefficient billing or illegal connections, as well as physical losses. Thus high levels of unaccounted-for water (or low levels of accounted-for water) indicate poor system management and/or poor commercial practice as well as inadequate pipeline maintenance. Tynan and Kingdom (2002) recommend a target of 23 percent (or less) for unaccounted-for water, on the basis of performance of the top 25 percent of developing countries. The mean for developed countries is 16 percent. The average unaccounted-for water ratio for Peru is 46 percent, which is significantly higher than the suggested target.

Coelli et al. (2003) regard water loss as an indicator of the technical quality of service, which has been ignored by many studies. In addition, coverage is used as an indicator of service quality because it is a direct measure of water availability to citizens in a municipality. The average coverage for Peru is 78.38 percent. A positive rate of chlorine tests (percentage of samples with satisfactory residual chlorine) ${ }^{7}$ and continuity of service are two of the three indicators used by SUNASS to evaluate service quality, but the percentage of water receiving chemical treatment is not included in this study because of serious problems with missing observations. An unbalanced six-year panel data sample with 198 observations is used in the estimation. The

\footnotetext{
${ }^{7}$ Percentage of Samples with satisfactory residual chlorine is measured as a percentage of the sample with the residual chlorine found in the water satisfied the minimum requirements.
} 
monetary unit variables (both the cost and price variables) have been adjusted by using the GDP

Deflator. The variables are summarized in Table 1.

Table 1. Sample summary statistics

\begin{tabular}{|l|l|l|l|l|} 
Variable & Mean & Standard Deviation & Minimum & Maximum \\
\hline Cost & 9896591 & 15529449 & 157009 & 73537002 \\
\hline Input Prices & & & & \\
\hline Wage & 15656 & 5666 & 3573 & 48007 \\
\hline Price of Capital & 53.87 & 61.51 & 0.267 & 452.6 \\
\hline Outputs & & & & \\
\hline Water Billed (m3) & 6464635 & 8130557 & 103270 & 32990614 \\
\hline Number of customers & 135053 & 175889 & 6908 & 809158 \\
\hline Quality Indicators & & & & \\
\hline Accounted-for water ratio (\%) & 53.94 & 16.37 & 8.36 & 100 \\
\hline Coverage (\%) & 78.38 & 13.66 & 26.00 & 100.00 \\
\hline Positive rate of chlorine tests (\%) & 85.41 & 17.89 & 4.32 & 100.00 \\
\hline Continuity of service (hours/day) & 15.05 & 5.71 & 2 & 24 \\
\hline
\end{tabular}

\section{Estimation and results}

\subsection{Stochastic cost frontier model}

The cost frontier is chosen because it can accommodate multiple outputs easily; the frontier approach recognizes that not all utilities try to minimize their costs for reaching a given output level.

The stochastic cost frontier can be expressed as

$C_{i}=C\left(y_{i}, w_{i}, \beta\right) \cdot \exp \left\{\varepsilon_{i}\right\}$

where $y_{i}$ is the scalar output of producer $i, i=1, \ldots, N, w_{i}$ is an input price vector faced by producer $i$, $C\left(y_{i}, w_{i}, \beta\right)$ is the cost frontier common to all producers, which determines the minimum cost achievable for a given set of outputs, input prices and control variables. $\beta$ is a vector of technology 
parameters to be estimated. In the stochastic cost frontier, the error term can be decomposed in two parts in order to incorporate producer-specific random shocks into the analysis.

$\varepsilon_{i}=u_{i}+v_{i}$

where $u_{i}$ is a positive one-sided disturbance that captures the effect of inefficiency and $v_{i}$ is a symmetric disturbance that reflects the random shocks on each producer. By taking the natural logarithms of both sides, equation (1) can be written as:

$\ln C_{i}=\ln C\left(y_{i}, w_{i}, \beta\right)+u_{i}+v_{i} \quad \quad \mathrm{i}=1, \ldots, \mathrm{N}$,

where $\quad C_{i}$ is the cost of the $i^{\text {th }}$ firm,

$y_{i}$ is a vector of output quantities of the $i^{\text {th }}$ firm,

$\mathrm{w}_{\mathrm{i}}$ is a input price vector faced by producer $\mathrm{i}$,

$\beta$ is an vector of unknown parameters,

$v_{i} \sim$ iid $N\left(0, \sigma_{v}^{2}\right)$,

$u_{i} \sim$ iid $N^{+}\left(0, \sigma_{u}^{2}\right)$ (half-normal model),

or $u_{i} \sim$ iid $N^{+}\left(\mu, \sigma_{u}^{2}\right)$ (truncated normal model),

or $u_{i} \sim$ iid exponential (exponential model),

$v_{i}$ and $u_{i}$ are distributed independently of each other, and of other regressors.

Different distribution models are tested in the study in order to reduce the impact of choosing a specific distribution function arbitrarily. Battese and Coelli (1995) proposed a conditional mean efficiency model based on a truncated normal model to identify some of the reasons for differences in predicted efficiencies among firms in an industry. The model can be expressed as: 
$\mu_{i}=z_{i} \delta$

where $\mu_{i}$ is the mean parameter of the truncated normal distribution of the truncated normal model, $\mathrm{Z}_{\mathrm{i}}$ is a vector of environmental variables, which may influence the efficiency of a firm, and $\delta$ is a vector of parameters to be estimated.

Coelli et al. (1999) suggest that the literature offers two alternative approaches to the inclusion of the environmental variables. One assumes that environmental factors influence the shape of the technology and hence that these factors should be included directly into the cost functions as regressors. The other approach assumes that environmental factors directly influence the degree of technical efficiency and hence should be included in equation (4). Both of these forms are tested here. The quality variables are considered either as environmental variables that may influence the efficiency of a firm or as additional outputs of the cost function. Caudill et al. (1995) point out that the size-related heteroskedasticity of the inefficiency variable $u_{i}$ may cause the frontier estimation to be biased. The inefficiency term embodies factors "under firm control" and larger firms may have more under their control. To correct the heteroskedasticity, they proposed a model based on the half-normal and exponential models noted above.

$\sigma_{u}^{2}=\exp \left(m_{i} \gamma\right)$

In this study, $m$ is the proxy for firm size--log of number of connections.

Battese and Coelli (1992) proposed the time-variant models to deal with the panel data in SFA analysis. However, as Coelli et al. (2003) point out, the time-varying efficiency model restricts the technical efficiency of all firms so that they follow the same trend direction; that is, either all 
increasing over time or all decreasing over time, which is unlikely to be valid in many instances. In the time invariant models (fixed effect, random effect and MLE models), the inefficiency is assumed to be constant over time. Since this study uses a six-year panel, this assumption seems unrealistic. Therefore, on that basis of recommendations by Coelli et al.(2003) and Estache et al. (2004), a time trend is added to the cost function to capture the technical change, and the equation ${ }^{8}$ can be expressed as:

$\ln C_{i t}=\ln C\left(y_{i t}, w_{i t}, t, \beta\right)+u_{i t}+v_{i t}$

\subsection{Estimation result:}

First, we estimate the frontier model without quality variables. Because all three models (with different error specifications) yield similar results, only the results of the half-normal model are reported here (Table 2). From the results we can see that all the coefficients of outputs and input prices are significant and consistent with economic theory: more outputs or higher input prices will result in higher costs. The coefficient of the time trend variable is insignificant, which suggests the absence of technological change over this time period. From the results, it also appears that the variance of the inefficiency term is a function of firm size, since size exerts a

\footnotetext{
${ }^{8}$ A detailed description of the maximum likelihood estimation procedure and log-likelihood function is available in Kumbhakar and Lovell (2000). Although the translog function is a flexible functional form often used in SFA studies, it frequently violates the assumption required in the cost function, such as monotonicity or concavity. Furthermore, translog functions can create a multicollinearity problem, which influences the statistical significance of the model. In fact, the present study finds very serious multicollinearity problems from the correlation matrix of the interactive terms. Many correlations exceed 0.8 even 0.9 . More importantly, given our sample size, the translog functional form consumes too many degrees of freedom (there would be 44 interactive terms in this case). Therefore, the Cobb-Douglas log linear form is adopted in this study.
} 
significant and negative impact on the variance of inefficiency.

Table 2: Half-normal model with no quality variables

\begin{tabular}{|c|c|c|c|c|c|c|}
\hline $\begin{array}{l}\text { Stoc. frontier } \\
\text { Log likelihood }\end{array}$ & \multicolumn{3}{|c|}{ normal/half-normal model } & \multicolumn{2}{|c|}{$\begin{array}{l}\text { Number of obs }= \\
\text { Wald chi2 } 2(5)=\end{array}$} & $\begin{array}{l}191 \\
5030.75 \\
0\end{array}$ \\
\hline $\log \cos t \mid$ & Coef. & Std. Err. & $\mathrm{z}$ & $\mathrm{P}>|\mathrm{z}|$ & {$[95 \%$ Conf. } & Interval] \\
\hline \multicolumn{7}{|l|}{$\log \cos t$} \\
\hline logvolumebilled | & .2480381 & .065844 & 3.77 & 0.000 & .1189862 & 0.3770899 \\
\hline logcustomer & .8431401 & .0649676 & 12.98 & 0.000 & .7158059 & 0.9704743 \\
\hline logwage & .1917949 & .0496641 & 3.86 & 0.000 & .094455 & 0.2891347 \\
\hline $\operatorname{logK}$ price & .3238125 & .0233191 & 13.89 & 0.000 & .2781079 & 0.369517 \\
\hline & -.0135769 & .0118493 & -1.15 & 0.252 & -.0368011 & 0.0096474 \\
\hline _cons $\mid$ & -1.126511 & .5198861 & -2.17 & 0.030 & -2.14547 & -0.1075534 \\
\hline \multicolumn{7}{|l|}{$\ln \operatorname{sig} 2 v$} \\
\hline _cons $\mid$ & -4.206636 & .2692258 & -15.62 & 0.000 & -4.734309 & -3.678963 \\
\hline \multicolumn{7}{|l|}{$\operatorname{lnsig} 2 \mathrm{u} \quad$} \\
\hline logconnection | & -.9099408 & .1760426 & -5.17 & 0.000 & -1.254978 & -0.5649036 \\
\hline _cons $\mid$ & 6.633958 & 1.604359 & 4.13 & 0.000 & 3.489472 & 9.778444 \\
\hline sigma_v & .1220508 & .0164296 & & & 0.093747 & 0.1588998 \\
\hline
\end{tabular}

Next, a panel data conditional mean efficiency model is estimated to check the impact of quality indicators on water utility efficiency. Again, the coefficients of outputs and input prices are significant and consistent with economic theory: more outputs or higher input prices will result in higher costs. The coefficient of the log connection is negative and significant, which reflects the decrease of inefficiency with the size of the utility. Three of the four quality indicator coefficients are positive, which means that the improvements in quality raise cost. However, none of the four coefficients is statistically significant, as shown in Table 3 . Therefore, it may not 
be appropriate to treat the quality variables as environmental variables.

\section{Table 3: Conditional mean efficiency model}

\begin{tabular}{|c|c|c|c|c|c|c|}
\hline Stoc. frontier & \multicolumn{2}{|c|}{ normal/truncated-normal } & \multirow[t]{2}{*}{ model } & \multicolumn{2}{|c|}{ Wald chi2 $2(5)=$} & $\begin{array}{r}191 \\
4895.39\end{array}$ \\
\hline Log likelihood & \multicolumn{2}{|r|}{0.36016228} & & \multicolumn{2}{|c|}{ Prob $>$ chi $2=$} & 0 \\
\hline $\log \cos t$ & Coef. & Err. & $\mathrm{z}$ & $\mathrm{P}>|\mathrm{z}|$ & {$[95 \%$ Conf. } & Interval] \\
\hline \multicolumn{7}{|l|}{$\log \cos t$} \\
\hline logvolumebilled | & .3048852 & .0706705 & 4.31 & 0.000 & .1663735 & 0.443397 \\
\hline logcustomer & .7835414 & .0684536 & 11.45 & 0.000 & .6493748 & 0.917708 \\
\hline logwage & .1822664 & .0498808 & 3.65 & 0.000 & .0845018 & 0.280031 \\
\hline $\operatorname{logKprice} \mid$ & .317059 & .0235598 & 13.46 & 0.000 & .2708826 & 0.363236 \\
\hline & -.0147467 & .0114495 & -1.29 & 0.198 & -.0371872 & 0.007694 \\
\hline _cons & -1.152364 & .5477089 & -2.1 & 0.035 & -2.225854 & -0.078875 \\
\hline \multicolumn{7}{|l|}{$\mathrm{mu}$} \\
\hline logconnection | & -.9588774 & .482736 & -1.99 & 0.047 & -1.905023 & -0.012732 \\
\hline logpositive & .234255 & .4060676 & 0.58 & 0.564 & -.5616229 & 1.030133 \\
\hline $\log$ count & -.3751222 & .3477529 & -1.08 & 0.281 & -1.056705 & 0.306461 \\
\hline logcontinuity & .1380695 & .2075654 & 0.67 & 0.506 & -.2687512 & 0.54489 \\
\hline logcoverage & 2.443438 & 1.484034 & 1.65 & 0.100 & -.4652143 & 5.352091 \\
\hline _cons & -2.729699 & 5.055498 & -0.54 & 0.589 & -12.63829 & 7.178896 \\
\hline /lnsigma2 | & -.9439441 & .5616719 & -1.68 & 0.093 & -2.044801 & 0.156913 \\
\hline /ilgtgamma | & 3.046993 & .615609 & 4.95 & 0.000 & 1.840421 & 4.253564 \\
\hline sigma2 | & .3890902 & .218541 & & & 0.129406 & 1.169893 \\
\hline gamma | & .9546525 & .0266504 & & & 0.8629985 & 0.985986 \\
\hline sigma_u2 | & .3714459 & .2182481 & & & -0.0563124 & 0.799204 \\
\hline sigma_v2 | & .0176443 & .0039789 & & & 0.0098458 & 0.025443 \\
\hline
\end{tabular}

To explore this specification issue, quality variables were treated as additional outputs and included in the cost function. The results (half-normal model) are shown in Table 4. All the coefficients of the four quality variables are positive and significant at the 0.1 level, which means 
that the quality comes at a cost. The higher the quality level, the higher the cost. The coefficients

of the accounted-for water rate, continuity and service coverage are significant at the 0.05 level.

Table 4: Half-normal model with quality variables as outputs

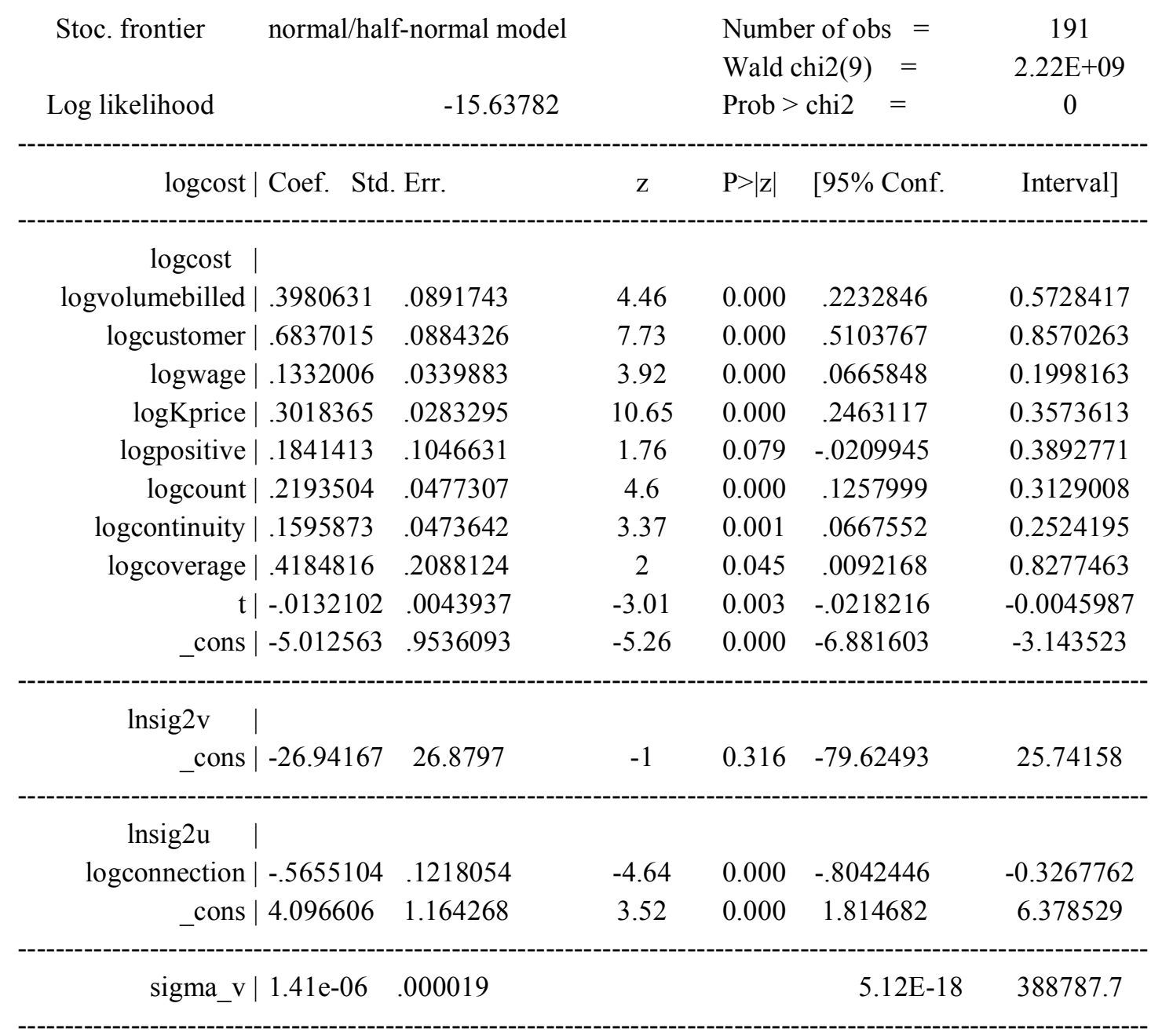

The results indicate that the quality output variables should be included in cost frontier models; otherwise, firm rankings will be biased against those firms providing higher levels of service quality. Again, the variance of inefficiency is a function of firm size. The results are 
confirmed by additional model estimates using the exponential model with and without quality outputs (available from the author). For the normal/exponential stochastic frontier model, all of the coefficients of input prices and outputs are consistent with economic theory. The results are similar to those obtained in the half-normal model presented above.

However, when quality variables are included as additional outputs, the results are not similar to those obtained in the half-normal model. The coefficients of positive chlorine test rate, accounted-for water, and continuity become statistically insignificant. The coefficient of service coverage is still positive and significant at the 0.05 level. To check whether or not the inclusion of quality variables in the cost frontier is necessary, a log-likelihood ratio test was conducted and a Wald test performed, with the null hypothesis that all four coefficients of the quality variables are equal to zero simultaneously. Both tests reject the null hypothesis at the 0.01 level. Therefore, quality outputs should not be ignored in the cost frontier.

The four models described here are all used to determine whether the inclusion of quality variables changes the benchmarking result. For simplicity, consider the relative performance of utilities in 2001. The efficiency values and rankings for the four models are reported in Table 5. 


\begin{tabular}{|c|c|c|c|c|c|}
\hline \multicolumn{7}{|c|}{ Table 5: Correlations of efficiency rankings (n=36) } \\
\hline & & Half-norm & Exp & Half-quality & Exp-quality \\
\hline \multirow{3}{*}{ Half-norm } & Spearman Correlation & 1.000 & 0.977 & 0.833 & 0.943 \\
\cline { 2 - 6 } & Sig. (2-tailed) &. & $1 \mathrm{E}-06$ & $1 \mathrm{E}-06$ & $1 \mathrm{E}-06$ \\
\cline { 2 - 6 } & & & & & \\
\hline \multirow{3}{*}{ Exponential } & Spearman Correlation & 0.977 & 1.000 & 0.787 & 0.954 \\
\cline { 2 - 6 } & Sig. (2-tailed) & $1 \mathrm{E}-06$ &. & $1 \mathrm{E}-06$ & $1 \mathrm{E}-06$ \\
\cline { 2 - 6 } & & & & & \\
\hline \multirow{3}{*}{ Halfquality } & Spearman Correlation & 0.833 & 0.787 & 1.000 & 0.829 \\
\cline { 2 - 6 } & Sig. (2-tailed) & $1 \mathrm{E}-06$ & $1 \mathrm{E}-06$ &. & $1 \mathrm{E}-06$ \\
\cline { 2 - 6 } & & & & & \\
\hline \multirow{2}{*}{ Expquality } & Spearman Correlation & 0.943 & 0.954 & 0.829 & 1.000 \\
\cline { 2 - 6 } & Sig. (2-tailed) & $1 \mathrm{E}-06$ & $1 \mathrm{E}-06$ & $1 \mathrm{E}-06$ &. \\
\hline
\end{tabular}

Table 5 indicates that the correlations between the models with and without quality variables are significant. The result is not surprising because the physical outputs and input prices explain most of the variance in the models. As expected, the correlation between the half-normal model and half-normal quality model (half-normal with quality outputs) is lower than that between the exponential model (Exp in table 5) and Exp-quality model. Some statistically significant quality variables are in the half-normal quality model. The rankings for 2001 presented in Table 6 are similar across models, but the different specifications have significant impacts for some firms. Thus, a full analysis would look at trends over time and create groupings of firms (based on efficiency parameters), so undue emphasis is not given to ordinal rankings. 
Table 6: Efficiency Ranking of Peru Water Sector, 2001:Four Specifications

\begin{tabular}{|c|c|c|c|c|c|}
\hline & Firms & Half-norm & Half-qual & $\exp$ & Exp-qual \\
\hline 1 & EPS NOR PUNO S.A. 2001 & 36 & 36 & 36 & 36 \\
\hline 2 & EMAPA Y S.R.LTDA. & 33 & 33 & 33 & 34 \\
\hline 3 & EMAPAB S.R.LTDA. & 25 & 13 & 25 & 23 \\
\hline 4 & EMAQ S.R.LTDA. & 35 & 31 & 34 & 33 \\
\hline 5 & EMUSAP AMAZONAS & 23 & 24 & 23 & 26 \\
\hline 6 & SEMAPA HUANCAVELICA & 6 & 8 & 13 & 4 \\
\hline 7 & EMAPAU S.R.LTDA. & 32 & 30 & 32 & 32 \\
\hline 8 & EMAPAT S.R.LTDA. & 31 & 34 & 30 & 30 \\
\hline 9 & EMAPAVIGSSA. & 28 & 32 & 28 & 28 \\
\hline 10 & EPS SIERRA CENTRAL S.A. & 24 & 25 & 24 & 25 \\
\hline 11 & EMUSAP ABANCAY S.A. & 29 & 27 & 29 & 29 \\
\hline 12 & EMPSSAPAL S.A. & 27 & 26 & 27 & 27 \\
\hline 13 & EPS MOYOBAMBA S.R.LTDA. & 19 & 10 & 20 & 17 \\
\hline 14 & EPS MANTARO S.A. & 34 & 35 & 35 & 35 \\
\hline 15 & EPS SEDA ILO & 20 & 16 & 21 & 22 \\
\hline 16 & EMAPA HUARAL S.A. & 17 & 14 & 17 & 16 \\
\hline 17 & EPS CHAVIN S.A. & 15 & 20 & 15 & 21 \\
\hline 18 & EMAPACOP S.A. & 1 & 1 & 5 & 10 \\
\hline 19 & EPS SELVA CENTRAL S.A. & 16 & 3 & 16 & 14 \\
\hline 20 & EMAPA CANETE S.A. & 4 & 7 & 7 & 8 \\
\hline 21 & EMAPA HUACHO S.A. & 2 & 5 & 4 & 12 \\
\hline 22 & SEDA HUANUCO & 26 & 23 & 26 & 24 \\
\hline 23 & EMSA PUNO S.A. & 30 & 28 & 31 & 31 \\
\hline 24 & SEDACAJ S.A. & 10 & 11 & 12 & 9 \\
\hline 25 & EPS AYACUCHO S.A. & 22 & 18 & 22 & 19 \\
\hline 26 & EPS SEMAPACH S.A. & 14 & 17 & 14 & 13 \\
\hline 27 & SEDAJULIACA S.A. & 21 & 12 & 18 & 18 \\
\hline 28 & EMAPA SAN MARTIN S.A. & 18 & 29 & 19 & 20 \\
\hline 29 & EMFAPATUMBES & 8 & 4 & 9 & 5 \\
\hline 30 & SEDA CUSCO S.A. & 9 & 19 & 8 & 15 \\
\hline 31 & EPS LORETO S.A. & 12 & 2 & 11 & 6 \\
\hline 32 & EPS TACNA S.A. & 11 & 15 & 10 & 11 \\
\hline 33 & SEDA CHIMBOTE & 5 & 9 & 2 & 2 \\
\hline 34 & EPSEL S.A. & 13 & 22 & 6 & 7 \\
\hline 35 & SEDALIB & 7 & 21 & 3 & 3 \\
\hline 36 & EPS GRAU S.A. & 3 & 6 & 1 & 1 \\
\hline
\end{tabular}


In half normal/half-quality models, although the correlation is very high, some firms have quite different rankings under different models. For examples, firm 35 ranks $7^{\text {th }}$ in the halfnormal model and $21^{\text {st }}$ in the half-quality model. Firm 19 ranks $16^{\text {th }}$ in the half-normal model and $3^{\text {rd }}$ in the half-quality model. Firm 3 ranks $25^{\text {th }}$ in the half-normal model and $13^{\text {th }}$ in the half-quality model. Therefore, the inclusion of quality as an output (and the specification of error terms) can affect performance rankings. If rankings or scores are to be utilized in regulatory proceedings, great care must be taken to avoid unduly penalizing utilities (and managers) who seem to have high costs but provide higher levels of service quality. A key issue is how to incentivize managers to move their firms to the frontier. SUNASS does not have mechanisms for rewarding or penalizing poorly performing firms, other than "naming and shaming" the latter. The issue then becomes one of how robust the rankings are to alternative model specifications. Ultimately, policy problem becomes one of comparing the incremental costs and benefits of further service quality improvements (including the weight to be given to misclassifying some percentage of the firms).

\section{Concluding Observations and extensions:}

Benchmarking has becomes a very important tool for a number of purposes:

- evaluating the effectiveness of the reforms over time,

- comparing the relative performance of different companies within a sector,

- informing citizens so they can exert pressure for improved performance, and

- providing information to regulatory bodies, helping them improve incentives. 
Empirical studies are beginning to provide insights into cost drivers and performance comparisons. The purpose of this study is to underscore the importance of including service quality in future work. This dimension of performance is especially important for the water and sewerage industry in developing countries, where poor coverage and low service quality characterize many nations. The results presented here show that it is necessary to incorporate the quality variables as additional output variables rather than as environmental variables. The ranking correlation is high between the models with or without the quality variables. However, rankings can change dramatically for specific utilities. Future research needs to address related problems: (1) What are the efficiency change, frontier change and quality change in the Peru water industry? (2) To what extent might a quasi-fixed capital cost model be more appropriate given the difficulty of actually adjusting capital in water sector (Garcia and Thomas, 2001)? As more data become available, and additional studies are performed, economists will gain a better understanding of the role of quality in this sector.

\section{References}

Alva, S.L. and J.L. Bonifaz (2001). "Eficiencia relativa en el servicio de saneamiento en el Peru durante el periodo 1998-2000: una aplicación del DEA.” Mimeo, Universidad del Pacifico

Ashton, J. K., 2000. Cost efficiency in the UK's water and sewerage industry. Applied Economics Letters 7, 455-458.

Battese, G.E., and T.J. Coelli, 1992. Frontier production functions, technical efficiency, and panel data: with application to paddy farmers in India, in: Gulledge, T.R., Lovell, C.A.K. (Eds.), 
International Applications of Productivity and Efficiency Analysis. Kluwer Academic Publishers, Boston, , and T.J. Coelli, 1995. A model for technical inefficiency effects in a stochastic frontier production function for panel data. Empirical Economics 20(2), 325-332.

Caudill, S.B., J.M. Ford, and D.M. Gropper, 1995. Frontier estimation and firm-specific inefficiency measures in the presence of heteroscedasticity. Journal of Business and Economics Statistics 13, 105-111.

Clarke, G. R.G., K. Kosec, and S. Wallsten, 2004. "Has private participation in water and sewerage improved coverage? empirical evidence from Latin America”. Working Paper 04-02, AEI-Brookings Joint Center for Regulatory Studies.

Coelli, T.J., A. Estache, S. Perelman, and L. Trujillo, 2003. A Primer on Efficiency Measurement for Utilities and Transport Regulators. World Bank Publications, Washington, D.C. , S. Perelman, and E. Romano, 1999. Accounting for environmental influences in stochastic frontier models: with application to international airlines. Journal of Productivity Analysis 11, 251-273.

Corton, M. L., 2003. Benchmarking in the Latin American water sector: the case of Peru. Utilities Policy 11, 133-142.

Cubbin, J., and G. Tzanidakis, 1998. Regression versus data envelopment analysis for efficiency measurement: an application to the England and Wales regulated water industry. Utilities Policy 7(2), 75-85. 
D. Giannakisa, T.Jamasbb and M. Pollitt, 2005. Benchmarking and incentive regulation of quality of service: an application to the UK electricity distribution networks. Energy Policy, 33, 2256-2271.

Estache, A., and M. A. Rossi, 2002. How different is the efficiency of public and private water companies in Asia? The World Bank Economic Review 16(1), 39-148. , and E. Kouassi, 2002. Sector organization, governance, and the inefficiency of African water utilities. World Bank Policy Research Working Paper 2890.

,and L. Trujillo, 2003. Efficiency effects of "Privatization" in Argentina's Water and Sanitation Services. Water Policy, 5 (4), 369-380

, M. A. Rossi, and C. A. Ruzzier, 2004. The case for international coordination of electricity regulation: evidence from the measurement of efficiency in South America. Journal of Regulatory Economics 25(3), 271-295.

, S. Perelman and L. Trujillo, 2004. "Measuring Efficiency-Quality Trade-offs: An Application to Brazil's Freight Railways”. VIIIth European Workshop on Efficiency and Productivity Analysis meeting, Oviedo, September 2003

, S. Perelman and L. Trujillo, 2005. Infrastructure Performance and Reform in Developing and Transition Economies: Evidence from a Survey of Productivity Measures. World Bank Policy Research Working Paper 3514, Feb.

Foster, Vivien (2005). Ten Years of Water Service Reform in Latin America: Toward an 
Anglo-French Model, The World Bank Group: Water Supply and Sanitation Sector Board Discussion Paper Series, Paper No. 3, January.

Garcia, S. and Thomas, A. (2001). "The Structure of Municipal Water Supply Costs: Application to a Panel of French Local Communities” Journal of Productivity Analysis 16: 5-29.

Hunt, L.C., and E. L. Lynk, 1995. Privatization and efficiency in the UK water industry: an empirical analysis. Oxford Bulletin of Economics and Statistics 57, 371-388.

Kirkpatrick, C., D. Parker, and Y.-F. Zhang, 2004. State versus private sector provision of water services In Africa: a statistical, DEA and stochastic cost frontier analysis. Working Paper No.70, Center on Regulation and Competition, University of Manchester.

Kumbhakar, S.C., and C. A. Knox Lovell, 2000. Stochastic Frontier Analysis. Cambridge University Press, U.K.

Saal, D.S, Parker, D., 2000. The Impact of Privatisation and Regulation on the Water and Sewerage Industry in England and Wales: A Translog Cost Function Approach. Managerial and Decision Economics 21(6): 253-268.

, Parker, D., 2001. Productivity and Price Performance in the Privatised Water and Sewerage Companies of England and Wales. Journal of Regulatory Economics 20(1): 61-90. , Scott Reid, 2004. Estimating Opex Productivity Growth in English and Welsh Water and Sewerage Companies: 1993-2003. Aston Business School Working Paper RP0434. 
, David Parker and Tom Weyman-Jones, 2004. Determining the Contribution of

Technical, Efficiency, and Scale Change to Productivity Growth in the Privatized English and

Welsh Water and Sewerage Industry: 1985-2000”, Aston Business School Working Paper

RP0433.

, David Parker, 2005. Assessing the Performance of Water Operations in the English and

Welsh Water Industry: A Panel Input Distance Function Approach. Aston Business School

Working Paper RP0502.

Sappington, D. 2005. Regulating Service Quality: A Survey. Journal of Regulatory Economics,

forthcoming

Seroa da Motta, R. And A.R.B. Moreira (2004), "Efficiency and regulation in the Sanitation

Sector in Brazil”, IPEA, Texto Para Discussao, No 1059

Tupper, H. C., and M. Resende, 2004. Efficiency and regulatory issues in the Brazilian water and sewage sector: an empirical study. Utilities Policy 12, 29-40.

Tynan, N., and B. Kingdom, 2002. "A water scorecard: setting performance targets for water utilities. Public Policy for the Private Sector,” The World Bank Group, April 2002.

Wallsten, Scott, and Katrina Kosec, 2005. "Public or Private Drinking Water? The Effects of Ownership and Benchmark Competition on U.S. Water System Regulatory Compliance and Household Water Expenditures.” AEI-Brookings Joint Center Working Paper 05-05, 
World Bank, 2003. "Private Participation in Infrastructure: Trends in Developing Countries in 1990-2001,"World Bank, Washington, D.C. 